\title{
How do you acculturate when neighbors are throwing rocks in your window? Preserving the contexts of Somali refugee housing issues in policy
}

\author{
Pauline B. Guerin ${ }^{1,2 \star}$, Bernard Guerin ${ }^{3}$ and Fatuma Hussein Elmi ${ }^{4}$ \\ ${ }^{1}$ Pennsylvania State University, Brandywine Campus, 25 Yearsley Mill Road, Media, PA 19063, United States. \\ ${ }^{2}$ Flinders University of South Australia, Sturt Road, Bedford Park SA 5042, Australia. \\ ${ }^{3}$ University of South Australia, Mawson Lakes Boulevard, Mawson Lakes SA 5095, Australia. \\ ${ }^{4}$ Waikato Somali Community, New Zealand.
}

\begin{abstract}
Accepted 8 January, 2013
Appropriate housing for refugees in Western countries is a major contributor to successful resettlement. Agencies responsible for refugee resettlement often find themselves contemplating whether to 1) house refugees close to each other (example, 'ethnic enclaves') or 2) disperse refugees to facilitate acculturation. We describe our community-based participatory research including in-depth interviews and ethnography with a Somali refugee community in New Zealand. We discuss four themes related to housing and the dilemma of where refugees should be housed. Themes included: the perception that housing was inadequate; a preference for housing to be located closer to services and family support; personal experiences of racism and discrimination, and a desire for improved consultation in relation to housing matters. We also describe methods for preserving the contextual detail of such complex issues for both policy and community development.
\end{abstract}

Key words: Refugee, housing, policy, contextualizing, community-based.

\section{INTRODUCTION}

Affordable and appropriate housing for refugees in Western countries is an important contributor to successful resettlement especially in terms of health and wellbeing, education, and employment (Blackman and Harvey, 2001; Calsyn and Winter, 2002). Housing itself has multiple functions, such as protection from environmental elements, serving as a safe haven and providing a meeting place while promoting family and community unity, and also providing a space to develop or revitalise cultural practices away from new influences (Cameron, 2000; Murdie, 1999; Pyke and Lowe, 1996).

There are many issues concerning housing for refugees or migrants when they arrive in a new country (Beresford, 2001; Chambon et al., 1997; Dion, 2001; Hulchanski, 1997; Kearns and Smith, 1994; Murdie et al., 1995; Peach, 1998; Roscigno et al., 2009; Zetter and Pearl, 1999). Many of these issues are interconnected with various other issues that arise from being a refugee

${ }^{*}$ Corresponding author. E-mail: pbg12@psu.edu. Tel: 610892 1377. Fax: 6108921402. or migrant. These include the likelihood of being poor, unemployed, having a large family, knowing very few people who have been residents for any length of time, and being unfamiliar with places and customs of the area. Many housing issues therefore arise from contact with other groups and people in a new country, and in the interactions that take place between the groups, whatever form these might take. The issues go beyond the structure and size of the house itself, and reflect the interactions, social relationships and community organization. Much research relating to refugee or migrant settlement concerns whether refugees or migrants should be:

1. housed together in suburbs or areas so they can be together (that is 'ethnic enclaves' or clustering) and segregated from the wider society or

2. dispersed away from one another as a strategy to facilitate acculturation (Bolt et al., 2008; De Jong and Vurkuyten, 1996; Flippen, 2001; Goodkind and FosterFishman, 2002; Johnson et al., 2002; Novac, 1996; Soholt, 2001; Zetter and Pearl, 1999).

This is often debated in terms of which strategy is the best, but this radically-polarised framing of the debate is 
indicative of the statements being used without documentation of context. In fact, neither of the options can be best, since it depends on contextual factors that have long been discarded even before statements about housing reach policy makers. However, the simplistic use of dichotomies is often prevalent in policy development.

\section{Refugees and housing in New Zealand}

In New Zealand at the time of this research, the settlement of humanitarian refugees was jointly co-ordinated by a non-Government organisation that provided services to refugees and the State housing department. While the refugee organisation looked after many of the basic needs of refugees, the Government-funded State housing agency looked after public housing-when it was available. Armed with NZ\$1500 to set up a new house (usually just enough to buy a washing machine and refrigerator), few refugees were lucky enough to be allocated a house from State housing-despite the stated policy eligibility criterion that all humanitarian refugees could obtain one. If there was not a house available from State housing, the task usually rested with staff or volunteers from the refugee organisation to help a family find a house to rent on the private market. Since the authors all worked in varying capacities with the refugee organisations, they all had intimate knowledge of the ins and outs of the services, such as the housing markets and the barriers and conflicts these families were likely to face. It was through these participatory and communitybased experiences that the need for systematic and intensively contextual documentation of the issues became apparent.

\section{Somali as refugees in New Zealand}

At the time this research was conducted the New Zealand total population was around four million. Approximately 1000 refugees were accepted into New Zealand annually, and from the early 1990s, Somali refugees began arriving through the United Nations High Commission for Refugees (UNHCR) programs. Other refugee groups living or arriving in New Zealand at that time included Cambodian, Iraqi, Iranian, Afghani, Congolese, Djibouti, Ethiopian, and Burmese. The New Zealand Somali population numbered about 2000 at the time of this project.

Somali, as a particular group, presented a number of points of interest for New Zealand and for research since Somali differed from most New Zealanders on many dimensions. For example, nearly all Somali were practicing Muslims and easily distinguished by veiling and other non-Western dress. They were also black Africans and there were very few other people of black African descent in New Zealand at that time, although there were other large non-white populations including Maori, Pacific
Islanders and Asians. These factors, combined, made Somali perhaps the most visible minority living in New Zealand. As well, the majority of Somali were multilingual, speaking many languages other than English, including Arabic, Italian and Somali.

Somali has been described as the most marginalised group in New Zealand (Bedford, 2004). During early resettlement, Somali experienced high unemployment rates, low educational attainment (due to their refugee historical context), language and cultural barriers, economic disadvantage and a reliance on the State for housing, and the plight of Somali people seemed insurmountable. Add to that discrimination and blatant racism, particularly after 9/11, and the outlook for Somali was bleak.

Many Somali people experienced difficulty in obtaining appropriate, affordable and sustainable housing. This provided the basis for the research, which aimed to systematically document:

What were the difficulties?

What was appropriate and affordable housing, and on whose terms?

Overall, the goals of the research were to systematically document the housing issues and to use this contextually-rich documentation to advocate for more appropriate policy, improved services, and appropriate, affordable and sustained housing.

\section{METHODS}

This research was conducted in a small town in New Zealand between 2000 to 2006 . The total population size of that town at that time was around 100,000 residents including approximately 800 Somali residents who had mostly arrived New Zealand via humanitarian pathways through United Nations High Commission for Refugees programs. The data presented in this paper were derived from two main research methods: ethnography and indepth interviews. We provide a conceptual discussion below justifying our methods as well as details of our approach. Ethical approval for this research was obtained from the University of Waikato Psychology Department Research Ethics Committee.

Much of the research relating to housing issues has relied on survey questionnaires, telephone surveys, or data gleaned from market research or from census data. Overall, these methods are brief and not very intensive in social interactions and relationships. While such data are useful for some purposes, especially when the research questions are very concrete and clear, many of the social issues requiring research evidence are either politically and socially very complex, or too abstract and complex. In these cases, the research methods need to be intensive and to consider a vast range of influencing factors (Guerin and Guerin, 2007). Observations and measurements that do not include detailed documentation of the context (such as those in surveys or structured interviews) often result in summary statements that are easily polarised. This in turn leads to those statements being applied in social policy and elsewhere in misleading ways. Contradictory policy directions are made often because the observations or summary statements upon which they are based are without context.

Therefore, to properly influence policy, intensive forms of research that preserve the context with detailed observations and 
documentation are necessary. This will lead to more flexible social policy formulation and more context-friendly solutions. Recently, this has become of greater importance, with governments and governing bodies requiring 'evidence-based policy'. While the reliance on evidence is good, the quality of the evidence can often be doubted, and poor or narrowly-defined evidence will in turn lead to poor policy development or overly-simplified policy.

What this means for the study of people who have moved to new countries as migrants or refugees is that the contexts for any broad generalisation need to be provided and not diluted as they rise through the government chains. This entails inclusion of community-based and action research approaches and advocacy by researchers to assist with designing appropriate policy. We suggest the use of "Contextual Tables" as a way to facilitate the development of appropriate policy.

\section{Ethnographic methods}

All of the authors were directly involved with the community in various capacities. The first author was employed part-time with the refugee organisation and assisted with resettlement of a large number of Somali families. This position involved the coordination of volunteers, liaising with State housing and other departments and agencies (such as the Education Department for Schooling and the St Vincent de Paul Society to organise donated furniture). Other community work, such as coordinating and providing health and fitness sessions for four years with Somali women and assisting with issues such as electricity supply, family reunion, and employment meant that this author was heavily involved with the community. The second author taught English as a volunteer to a group of Somali men, including many of the elders of the community, and also helped run a week-long camp for the Somali boys. The third author was an active member of the local Somali community organisation, a multi-lingual volunteer for the refugee organisation, and an employed interpreter for the interpreting service. Overall, collectively thousands of hours were spent talking and participating with the people in this community.

A special issue of interest is the fact that the authors were so involved in the community. From Western research perspectives this might be seen as a biasing issue for objectivity of data. However, from an ethnographic and community-based perspective, this is the only way to achieve meaningful data. While it might be possible to collect data through structured interviews and surveys without intensive participation with the community and gaining trust, those data are likely to consist of superficial responses that can be biased in other ways. Of course, the method of data collection depends on the types of information that need to be collected, so community-based and ethnographic methods may not always be necessary. But with vulnerable populations, the literature and vast experiences of researchers suggest that this approach is necessary and that the process may even be more important than the outcomes. Further, the ethnographic approach, when done properly, means that any data are checked several times by many different people with different perspectives within and outside of the community, and are not the result of a single, one-off hour-long interview, for example. It is good practice to provide copies of reports and papers to people in the community before they appear publicly, or to discuss the research results so that any biases or lack of diversity that may have crept in will be noticed and corrected. In any event, it is not the case that there is only one 'correct' version and that other versions are biased, but rather that the 'findings' should consist of multiple versions, each placed within its own unique context, and community-engaged involvement allows for this.

This project therefore combined a wide variety of ethnographic methods over a six-year period in order to gather information about housing as well as a small number of in-depth interviews. Working with the community in this way, and over so many years also meant that outcomes from the research, either directly or indirectly, could be observed. The main methods used were in the form of informal talks in a wide variety of contexts with many people, along with the many casual observations made when working alongside the community members. Visits to State housing offices with Somali community members were common and provided valuable, contextual data.

\section{In-depth interviews}

Semi-structured in-depth interviews were conducted with a sub-set of the Somali community $(n=4)$ to systematically document details and to confirm ethnographic observations and experiences. These interviews were conducted by a multi-lingual researcher (the third author) in a place convenient to the participants. An information sheet was orally discussed with the participants as we found this to be the most appropriate method of informing participants about the research and gaining their verbal consent to participate. Detailed notes were taken by the interviewer during the interviews and quotes were documented where possible. Following the interviews, the interviewer reviewed her notes and elaborated where needed.

\section{RESULTS AND DISCUSSION}

Four main themes or issues were identified through the ethnographic observations and from the interview data. First, housing was often perceived by Somali to be inadequate and this generally related to houses being too small for large families. Secondly, housing was seen to be inappropriate due to distance from services and family support. Thirdly, systematic observation and participant reports revealed many cases of racism and discrimination-from neighbours as well as State and private housing staff. Finally, the fourth theme was that consultation or negotiation was lacking but participants believed that improved consultation and negotiation about housing issues would alleviate some of the problems. Each of these themes will now be described to illustrate the complexities of the issues within their contextual details. Overall, the main concerns in housing are related to relationships and interactions with other people in society.

\section{Perceptions of inadequate housing}

The perception that housing was inadequate was often related to the size of the house. With an average of five to six children per family, and extended family either needing to live with the family due to illness, disability or language barriers, or simply preferring to live together, the typical three-bedroomed New Zealand home was inadequate and in many cases overcrowded. Inadequacies also included issues relating to health and disability. For example, one family with severely asthmatic children was placed in a house with extreme mould and dampness problems such that a butter knife was needed to scrape mould off the windows and doors-a health hazard for anyone, asthmatic or not.

Another family consisting of a single mother with five 
children was placed in a two-storey house. The mother had a known medical condition that was aggravated by going up and down the stairs. All the bedrooms were located on the upper level, which required her going up and down the stairs many times a day to carry out basic household chores. Multiple requests for a single-storey house were denied by the State housing authority. We arranged a meeting with the State housing staff to discuss the issue and to provide medical documentation. On presenting the medical certificate, the housing staff member looked at the certificate, rolled her eyes and said, "Anyone can get one of these. This doesn't mean anything." The mother left the office in tears (Field notes, Guerin). This example illustrates both an issue of inadequate housing as well as poor treatment by housing staff. The latter is discussed further below under experiences of racism and discrimination.

\section{Proximity of housing to services and family support}

The location of housing was important for most families, although there was contextual diversity in what families felt it was important to be close to. For example, some families with small children preferred to be close to schooling, while other families, with disabilities or health conditions, preferred to be close to health services or amenities such as shopping and chemists. Closeness to other Somali or other family, and their Mosque was important to many families. Most support came from other Somali people in the community; therefore being close to others in the community was of huge benefit for many families. Families were often relied on for help with children, supporting each other on visits to services such as medical, housing, and employment, assistance with translation, and other social visits. For one family, closeness to schooling was more important than closeness to other Somali. They preferred to live in an area close to a school that they wanted their children to attend (because they heard that it was particularly sensitive to issues for the Muslim students), even though this area was further away from where most of the community lived.

Another common consideration was the distance to services. While some government, health and other social services had offices in many suburbs, other services had only one main office in the Central Business District (CBD) of the city. While many people had cars, the distance seemed to present an insurmountable barrier requiring people, particularly recent arrivals, to go outside their comfort zones. One woman with five children commented,

"Yes, I have a car, but with five children I have to have a van that seats at least seven, and these are much more expensive than a small car. And then I have to buy car seats for all the smallest children. These are expensive and getting everyone out of the house to do anything is time consuming and exhausting! If I don't have to go out,
I don't!" (Field notes, Guerin).

We found that families, particularly women with small children, took a long time, sometimes years, to even feel comfortable or safe enough to go to their local playground with children, preferring to stay home. Home visiting services, such as those provided by midwives and Plunkett (infant and early childhood) nurses were important and highly valued under these circumstances.

Additionally, we noted that General Practitioners (GPs) were easily accessible in the suburbs (one of the few remaining in fact). Because the only hospital was centralised, and some people were reluctant to travel to the CBD, many Somali therefore relied on GPs for a range of issues and needs. This is common among refugee groups (Guerin et al., 2004; Guerin et al., 2003; Johnson et al., 2008; Mihalopoulos et al., 1999). Our research suggests that this is largely due to their proximate location. This is partly evidenced by Somali seeking support from GPs that may have been dealt with more appropriately by others, such as specialised mental health services (Guerin et al., 2004) or obtaining help with immigration issues. However, seeing a specialist or getting other help meant, among other things, new appointments and travelling to the city, as well as seeing new people. GPs also provided safe environments and regular contact with the same people, reducing anxieties around issues of trust and familiarity.

A 'one-stop shop' for refugee and migrant services was eventually located in the main suburb where many of the refugee and migrant families lived. The development of this service involved much debate over where the service should be located. Many people involved in the debate recognised the importance of community outreach, but also were working under the constraints of being understaffed to serve such a large and vulnerable population. It was eventually decided that locating the service close to where the most vulnerable refugees lived was most preferable and there happened to be a building available in that area. For Somali, importantly, this service was close to the Mosque and a large playground and ameliorated many of the issues concerning barriers to accessing services. Much work went into advocating for this service and for locating it close to where the majority of refugee families were living.

\section{Experiences of racism and discrimination}

Through the research process, and through the volunteer participatory work of the authors, the experiences of racism, exclusion and discrimination were not difficult to find-both from people in their neighbouring communities and from State and private housing staff. While the experiences of racism and discrimination are well known and documented in the literature, the contextual details often get lost in the push for general and abstract principles from which to work (Roscigno et al., 2009).

One of the repeated aims of staff working in the State 
housing office at this time was the need to 'manage expectations' of the Somali clients. This meant that housing staff were aware that the housing being offered was not adequate or satisfactory, and the way to 'manage' that was to 'manage expectations', rather than to find more appropriate accommodation. Over time, it was discovered that the provision of inadequate housing to Somali families was not always due to a lack of housing available. Staff and volunteers of the refugee services agency were expected to assist clients by getting them to accept that they would have to live in a house of three bedrooms for 10 or more people, or that a large family with teenagers might have to live in two separate houses-that is, to 'manage expectations'.

The ethnographic observations also identified that State housing staff often used the phrase, 'The policy says ...' to justify not only their inaction, their decisions, or their poor service, but this was often coupled with a lack of documentation in the clients' files. Therefore, when a new staff member took over the files they had no record of the number of visits, the requests for housing or changes to housing and why, or the reasons for visits. Finally, completely inappropriate housing was offered at times, and if the family did not accept that house then it was claimed to be no longer the responsibility of the State housing staff to find a house for that family because they had already offered a house that was not accepted. Families were often in a disempowering circumstance not much improved from their previous refugee experiences.

The question arose about whether service providers had been provided training about racism, discrimination or culturally sensitive practice. Had some of these providers been 'racist' all along, or did their practices become more racist over time? (Cropley, 2002). Service providers were often under a great deal of pressure to allocate few houses to many people. Informal interviews were therefore conducted with service providers and others connected with the services, and we discovered that they received only a small number, if any, of cultural awareness training sessions of some sort. While this type of training does serve a role, these sessions alone are not likely to reduce discriminatory interactions between staff and clients, especially when 'key informant' interviews revealed that there was a 'backroom culture' of jokes and making fun of the refugee clients. Relaying good strategies and approaches to policy makers through seminars, as well as presentations at various conferences about the issues contributed overall to greater awareness about the topic. This suggests that as a means of contributing to more relevant policy and programs, training should be less generalized or abstract (such as "cultural awareness") and be much more localized, utilizing specific local contexts and conditions.

Many families were housed in two particular cul-desacs where the anti-Somali climate was well known from issues around the initial settlement of Somali in the area. The story of one family is particularly illustrative of both the mistreatment by neighbours and the 'failure to act'which is, in itself, racist- of services such as State housing and the Police. The first and third authors both had multiple and close contact with this family through volunteer and other community involvement. This family consisted of a couple with four small children and another baby on the way, along with a sister of the husband. They were housed in a three-bedroom state house next door to two private houses, one of which was a long-suspected home for various illegal activities, such as drug dealing and gang involvement. While they did have other family living in town, they were not housed close to them.

The mother (we will call her Amina) was due to have their baby within only four weeks of arriving. During those weeks, she was attacked by the woman next door when she opened her door to the woman's knocking. The children were called names, and although they arrived speaking no English, the children soon learned the expression 'Fuc ${ }^{* * *}$ Black' and how to wave their middle finger at the local children, erroneously thinking this was a form of greeting. The family immediately requested that they be moved to a different house in a different neighbourhood, perhaps closer to their family for support with children. The abuse continued, however, and was even observed on at least one occasion by the State housing staff member in charge of the house.

Police were called regularly to attend the violence, with mixed responses to the situations by the attending officers. On one occasion Amina's children were playing video games in the house with the window open when neighbourhood children threw rocks through the window, hitting the children on the head. Amina phoned the police and in her broken English said, 'they kill my children'. She also phoned the first author, very distressed, saying once again, 'they kill my children'. The first author arrived at her house, just after three police cars had arrived, to find Amina very upset and trying to explain to the police what had happened. The police advised her that if she did not calm down they would have to arrest her and take her to the station, which only served to further aggravate the situation. With the author's help it was soon realized that when Amina said 'kill', she was using whatever English word she could think of in her distressed state that indicated that harm had been inflicted on her children.

Although most of the violence and maltreatment came from the teenagers in the street, no one seemed to be able to do anything about it. Despite there being youth workers from the city council, the Police, and the State housing staff, no one seemed to have the authority or the skills to manage the situation, and the response was always that it was 'someone else's job' to deal with it. For example, the police would say that the housing agency should deal with the situation, since it was about housing; the housing agency would say the migrant service should deal with it because it involved refugees; the migrant service would say the city council should deal with it because it was a youth issue.

One day, the first author was at the house with Amina while the group of youths who were often the source of problems were seen in the vacant lot across the street. Amina indicated that it was those boys who would swear 
at them and throw things. The first author directly approached the boys and asked them what was going on. They replied, pointing to Amina's house, that 'They started it, tell them to stop'. The first author negotiated with the boys, requesting that they all try to get along, or at least to stop the abuse. She told them that she would also talk to Amina's family to make the same request. This was agreed by all to be a good plan, and for at least eight months there was no trouble between the local youths and Amina's family. What is surprising in this situation was not that the author had special powers in conflict resolution, but that it only took one conversation, by someone, to acknowledge and address the problem.

Issues with the adult neighbors continued, however, with incidents such as the destruction of the post box, and the neighbours driving through the front yard. Charges were filed and mediation was attempted. Amina and her family lived in this dire situation for three years before State housing found them a four-bedroom house only one block away. Interestingly, moving just this one block away completely stopped all instances of abuse. The children could stay in the same school so there was little disruption for their schooling. However, it is difficult to know how much damage living under those conditions had on the family and how much more successful their settlement could have been if they did not have to contend with that kind of abuse.

In terms of property owners or rentals via the private market, the nature of discrimination mostly involved not renting to 'these people', based on racial or ethnic assumptions - such as the assumption that they will cook smelling food, or that they will have lots of visitors and 'wreck the place'. Finally, there was the 'exploitation by landlords'. This latter issue became apparent, for example, through not meeting obligations as property owners. In one household for example, when the shower did not work the property owner hung a garden hose in the bathroom connected to the cold water. Frequent dishonest use of bond payments was evident, as most renters did not have the English to query or challenge the costs, but were also unaware of their legal rights. For many Somali, it was simply too hard to try to do something about it.

One interviewee in the in-depth interviews described the impact on his social life of the discrimination coupled with living in a bad neighbourhood:

I had my house burgled the second day I moved in. Three weeks later, the unit attached to mine was burnt down by irate ex-tenants. I had to be woken by neighbours in the middle of the night. I have had my car stolen and crashed. It's beyond repair and it was not insured and the so-called offenders are young people, which means they will not pay for the crime committed. My visitors' car was broken into and windows smashed when my car was stolen. So not only my life is in danger, but I'm not receiving visitors any more as everyone is concerned for their cars and safety. This is starting to affect my social life because prior to moving to this house
I used to have lots of elderly visitors. We used to watch the news and what's happening in Somali. But now no one wants to take the risk of coming to my house.

The final point about racism and discrimination is that while another argument of the 'dispersal versus segregate together' dichotomy is that refugees will learn more about the language and practices of their host country if dispersed rather than 'segregated together', experiences of racism and discrimination frequently prevent learning from neighbours and others. As an example, there was a case in which a New Zealand woman phoned the housing agency. She lived next door to a Somali family and she wondered if she could talk to a Somali elder or someone from the Somali community. The woman was referred by the housing agency to a Somali Elder. The woman explained to the Elder that her refrigerator was broken and she had medication that needed to be refrigerated. Would he ask her neighbours if they would refrigerate her medication for her? This was a very curious situation indeed, but illustrates the hesitation of at least some people to even talk to their neighbours. Proximity does not guarantee social interaction (Guerin and Guerin, 2009).

\section{Lack of consultation or inadequate consultation}

'Consultation' seemed to be the buzz word for departments and agencies in the 1990s and 2000s, and perhaps even continues to be. But from our observations, 'consultation' took on one meaning for departments and agencies, and another for people in the community. In this research, participants reported a general lack of 'consultation' or communication between themselves and the agencies or departments. Consultation with Somali or refugees in general can be difficult-for a number of different reasons. English is often not the first language for refugees, and government services are often lacking the skills or capacity to reduce language barriers.

As an example, one of the authors had gone to a State welfare office with a Somali woman with one of her family members acting as an interpreter. As they were discussing an issue with a case manager, another Somali woman had come to the office for assistance with another issue and was trying to explain this to her case manager who did not have the skills to understand the situation. $\mathrm{He}$ (the other case manager) approached the woman who was acting as an interpreter and asked her if she would help him. We explained that she was not a paid interpreter, but was there to help her aunt with a situation. We also showed him the telephone interpreting service card that was available at the reception desk and that explained how to phone the Somali interpreting phone line for assistance.

Consultation at a government, policy level, while wellintentioned, can backfire when poorly planned. For example, on one occasion we participated in a nationwide consultation process about refugee and migrant 
settlement where the meetings were not well advertised, were scheduled at times that prevented many people from attending and resulted in attendance by only the few people who were regularly 'consulted' on such issues, thereby biasing the 'consultation' process. At one of the meetings, the agenda and process were tightly controlled, leaving no time for any discussion. The 'consultation' involved people being shuffled into 'breakout' groups and told to write on large sheets things such as, 'The three most important settlement issues for you'. Overall, it seemed that the 'consultation' would result in superficial, well-rehearsed findings ('Housing is an important settlement issue). A number of the participants were very vocal in pointing out that the 'consultation' was a farce and that it was not appropriate for one or two members of a community to speak on behalf of everyone. All the points we have made above were stated publicly with many of the more subtle issues of settlement made.

At a more local level, there was a sincere attempt at consultation with the community in the case of the racial discrimination occurring in one neighbourhood. A particular community constable undertook an assessment in the neighbourhood where there was considerable racism and discrimination. He found that there were over 100 children living in that particular cul-de-sac. He took the time to speak to the residents and organised a gettogether for people in the street to identify solutions. It was planned that people would bring food and that attempts would be made to solve problems in the neighbourhood.

Although well-intentioned, unfortunately none of the 'problem' neighbourhood children or adults attended, and the core Somali adults were too busy with children and family matters to attend. What occurred was that a few people from the street attended, including a couple of long-time residents who did not know what the meeting was really about, ourselves, the policeman, staff from State housing and the refugee agency, and a few sundry residents from the street. It soon became obvious that we were 'preaching to the converted'. Unfortunately, the constable who organised the event moved on to a different job, and his experience went with him, and no further neighbourhood gatherings were organised.

On an action level, we did eventually get some policy changes occurring, but it was almost by accident. Because of our writings and activities in a variety of refugee groups and research projects, when the social policy people came to re-examine their settlement policies, the second author was sent a draft copy of the policy document and asked to comment (but note that the community was not asked). We wrote numerous paragraphs of contextual information on all issues, in consultation with community members. Where the segregate/ disperse issue arose, we added some 'It depends on...' contextual clauses, spelling out some conditions under which settlement will either work or not. From the response we received back the policymakers themselves seemed pleased to get some useful comments, and hopefully some people were made more aware of the issues that are left out by the earlier, rather polarising policy statements. This would also assist those interpreting and implementing the policy to do a better job than what we had observed over many years.

\section{GENERAL DISCUSSION}

Most of the common themes identified were similar to those identified through other forms of research-such as questionnaires, telephone surveys and casual observations. However, although the broad statements of the results are similar to other published research in the area, our data also provided a more detailed and contextualized understanding of the issues, and our approach meant that changes were made continually as the research progressed and contacts were made with people in agencies and departments where the changes needed to be made. The kinds of data generated by surveys or structured questionnaires result in overly simplistic policies or interventions. By contrast, the present research was able to provide context to the findings, show variations in what was found, depending upon context, and provide real stories to accompany the findings. The more socially intensive research methods have further levels or layers (Guerin and Guerin, 2007) of details or contexts that can be utilised when refining policy or carrying out interventions or actions. Policy makers and service agents should not have to rely on a single, abstract generalisation about an issue to derive policy and actions which then has to be implemented in a real context.

The research identified many difficulties in accessing housing: discrimination by state housing staff and private rental owners, language barriers, financial barriers, and transport. The research also found that there was a mismatch between what Somali viewed as appropriate and affordable housing and the housing available, with what the housing staff viewed as being appropriate and affordable. An interesting finding was also that the mismatch between Somali expectations regarding affordable housing and that of State housing staff was not inconsistent with the actual policy. Rather, the presentation of policy given by State housing staff was inconsistent with the actual policies.

As a participative project, this project also revealed an 'action research' dynamic, in that as the researchers learned of the policies and legislation relating to housing it was shared with people in the community, thereby informing them and helping them to advocate for more appropriate housing and treatment. Near the end of this project we observed positive changes in the allocation of housing to resettling refugees. While it is difficult to determine the causes of these changes, it is perhaps indicative that at the start of the work almost no state housing was allocated to refugees on arrival, with housing almost completely obtained via means of private rentals. However, by the end of the project it was heartening to find that almost all families were housed in 
Table 1. A contextual table for the placement of refugee housing.

\begin{tabular}{|c|c|c|}
\hline Issues & Positive effects & Negative effects \\
\hline \multirow[t]{4}{*}{$\begin{array}{l}\text { Disperse refugee } \\
\text { housing }\end{array}$} & $\begin{array}{l}\text { Can be closer to key facilities such as } \\
\text { school }\end{array}$ & $\begin{array}{l}\text { Away from family and therefore family } \\
\text { support }\end{array}$ \\
\hline & $\begin{array}{l}\text { Can allow more choice of service } \\
\text { providers }\end{array}$ & $\begin{array}{l}\text { Further to travel to family and community } \\
\text { events and support }\end{array}$ \\
\hline & $\begin{array}{l}\text { Social support can be dispersed } \\
\text { across many providers }\end{array}$ & $\begin{array}{l}\text { Community events more difficult to } \\
\text { organize }\end{array}$ \\
\hline & $\begin{array}{l}\text { More chances of employment over a } \\
\text { wider area }\end{array}$ & $\begin{array}{l}\text { Community members can be isolated and } \\
\text { marginalised if they are the only ones from } \\
\text { their group in schools, employment and in } \\
\text { other situations }\end{array}$ \\
\hline \multirow[t]{6}{*}{$\begin{array}{l}\text { 'Segregate together' } \\
\text { for refugee housing }\end{array}$} & $\begin{array}{l}\text { Close to family, facilitating family } \\
\text { support }\end{array}$ & $\begin{array}{l}\text { Possible decreased interactions with non- } \\
\text { Somali, which may decrease acculturation }\end{array}$ \\
\hline & $\begin{array}{l}\text { Close to Mosque, facilitating } \\
\text { community support }\end{array}$ & $\begin{array}{l}\text { Service providers may be overwhelmed } \\
\text { Will generally be in poorer or low socio- }\end{array}$ \\
\hline & May decrease racist experiences & economic status areas \\
\hline & $\begin{array}{l}\text { Greater everyday social support is } \\
\text { available }\end{array}$ & $\begin{array}{l}\text { Employment opportunities in the area may } \\
\text { be depleted }\end{array}$ \\
\hline & Easier to consult 'whole' community & \\
\hline & $\begin{array}{l}\text { Decreased travel for social and } \\
\text { community support }\end{array}$ & \\
\hline
\end{tabular}

state housing (as per policy) on initial resettlement. The authors contributed to housing policy documents and presented research findings to 'End Users' meetings that included policy advisers across a range of state departments and agencies relevant to refugee and migrant issues. Of particular relevance was the forum provided by our research to enable critical analysis of assumptions underlying the question of where to house people-together or apart- to obtain 'successful' resettlement. We did not try to present simple statement summarizing our research, but presented the findings in the way we have done here, as a series of situations with many sides, giving ample illustrations of how different aspects play out in the real community and how to adjust policy to take this into account.

As a community-based research approach, it was important that participants gained something concrete from their participation. This is difficult for research projects that have their outcomes focused exclusively on extracting abstract or generalisable 'facts' (such as those for academic publications) that hold little or no benefit for the community in concrete ways. The active participation in the research by both researchers and community provided the means by which the researchers could serve as advocates and help to solve some of the complex problems experienced by individual participants and families, albeit on a micro or psychological level. In terms of a macro-level, this research was also part of a larger project that disseminated findings to Government policy makers, hopefully contributing to broader changes regarding housing issues in refugee resettlement.

By using both participatory methods (ethnography) and in-depth interviews, the project was able to identify issues and concerns of the community around acculturation that would not be found with other approaches, such as surveys, and maintain that richness when presenting the findings to policy makers and service providers. We believe that community-participation methods can add more concrete substance to the complexities of any sort of form of acculturation. Overall, we concluded that the entire participatory research process and the relationships created and developed were integral to the research and its successful action outcomes for the acculturation of individuals and the community, in all its innumerable forms. We also believe that these methods can add more substance that will assist policy makers to develop more realistic and flexible policies, and ones that can be implemented more appropriately.

\section{Segregation or Dispersal?}

Our research suggests that the answer to the question of whether to segregate or disperse refugee communities is, 'It depends...' The contextual detail is critical to answering this question in any particular case and to developing policies and programs. The main benefits come from placing community members nearby, but there are many exceptions and many other conditions tempering this broad statement. As well, many Somali had special needs arising from unemployment, trauma, and health, so they were especially sensitive to the distance from services and others.

We believe it is important from all the examples we have given that the rich contextual details remain when policy makers determine outcomes. This is difficult to do 
when academia strongly rewards abstract and generalizable statements as the best form of knowledge. We believe that gathering 'data' with the more intensive and close forms of methodologies is vital for this to occur (Guerin and Guerin, 2007), and we also advocate for summarizing research on such complex and important issues in the form of "Contextual Tables" rather than as generalized outcome statements (Guerin and Guerin, 2009).

A simple form of a "Contextual Table" is shown in Table 1 for the current issue. This puts the "knowledge" gained into a written form that can be quite detailed, and resists having a single generalized answer. It also allows the outcome that any side of the argument is not always best or worst but that with intervention both sides can be made to work. Finally, another advantage is that practitioners, those having to implement or work with such policy descriptions, can be far more flexible in the way they respond and the way they intervene to help. In most of the examples we have provided in this paper, this would have been advantageous to both the State housing staff and the Somali involved.

\section{ACKNOWLEDGEMENTS}

The data collection in this research was kindly supported by the Foundation for Research Science and Technology, Grant No.UOWX0203. We are grateful to the Somali participants who made it possible. Preparation of this manuscript and developing the ideas around policy, services and marginalised communities was supported by an Australian Research Council Grant DP0877901 to Bernard Guerin, Pauline Guerin, Deirdre Tedmanson and Yvonne Clark, 'Indigenous mental health in remote communities: Applying a contextual model of community research and intervention'.

\section{REFERENCES}

Bedford RD (2004). Out of Africa ... new migrations to Aotearoa. In G. Kearsley \& B. Fitzharris (Eds.), Glimpses of a Gaian world: Essays in honour of Peter Holland Dunedin: School of Social Sciences, University of Otago pp.345-381.

Beresford Q (2001). Homewest versus Aborigines: Housing discrimination in Western Australia. Aust. Abor. Stud. 2:40-46.

Blackman T, Harvey J (2001). Housing renewal and mental health: A case study. J. Ment. Health10:571-583.

Bolt G, van Kempen R, van Ham M (2008). Minority ethnic groups in the Dutch housing market: Spatial segregation, relocation dynamics and housing policy. Urban Stud. 45:1359-1384.

Calsyn RJ, Winter JP (2002). Social support, psychiatric symptoms, and housing: A causal analysis. J. Commun. Psychol. 30:247-259.

Cameron S (2000). Ethnic minority housing needs and diversity in an area of low housing demand. Environ. Plann. 32:1427-1444.

Chambon AS, Hulchanski JD, Murdie RA, Teixeira C (1997). Access to housing in a Canadian city: Experiences of three immigrant groups. Paper given at the Urban Affairs Association Conference, Toronto. [http://www.library.utoronto.ca/hnc/publish/index.htm]

Cropley A (2002). Problems and concerns of welfare paraprofessionals working with refugees. Br. J. Soc. Work 32:233-245.

De Jong W, Vurkuyten M (1996). Urban renewal, housing policy and ethnic relations in Rotterdam. New Commun. 22:689-705.
Dion KL (2001). Immigrants' perceptions of housing discrimination in Toronto: The Housing New Canadians Project. J. Soc. Issues 57:523-539.

Flippen CA (2001). Residential segregation and minority home ownership. Soc. Sci. Res. 30:337-362.

Goodkind JR, Foster-Fishman PG (2002). Integrating diversity and fostering interdependence: Ecological lessons learned about refugee participation in multiethnic communities. J. Community Psychol. 30:389-409.

Guerin B, Abdi A, Guerin PB (2003). Experiences with the medical and health systems for Somali refugees living in Hamilton. NZ J. Psychol. 32:27-32.

Guerin B, Guerin P (2007). Lessons learned from participatory discrimination research: Long-term observations and local interventions. Aust. Community Psychol. 19:137-149.

Guerin B, Guerin PB, Diiriye RO, Yates S (2004). Somali conceptions and expectations of mental health: Some guidelines for mental health professionals. NZ J. Psychol. 33:59-67.

Guerin B, Guerin P (2007). Research with refugee communities: Going around in circles with methodology. Aust. Community Psychol. 19:150-162.

Guerin B, Guerin P (2009). Fly in and fly out and drive in and drive out health and social services in remote communities. Aust. Community Psychol. 21(2):7-22.

Hulchanski JD (1997). Immigrants and access to housing: How welcome are newcomers to Canada? [http://www.library.utoronto.ca/ hnc/publish/index.htm].

Johnson DR, Ziersch AM, Burgess T (2008). I don't think general practice should be the front line: Experiences of general practitioners working with refugees in South Australia. Aust. NZ Health Pol. 5:20.

Johnson R, Poulsen M, Forrest $J$ (2002). Rethinking the analysis of ethnic residential patterns: Segregation, isolation, or concentration thresholds in Auckland, New Zealand. Geogr. Anal. 34:245-261.

Kearns R, Smith CJ (1994). The residential mobility experiences of marginalized populations. Tijdschrift voor Economische en Sociale Geografie 85:114-129.

Mihalopoulos C, Pirkis J, Naccarella L, Dunt D (1999). The role of general practitioners and other primary care agencies in transcultural mental health care. Melbourne: Australian Transcultural Mental Health Network.

Murdie RA (1999). The housing careers of Polish and Somali newcomers in Toronto's rental market. Housing Stud., 17:423-443. Also on: [http://www.library.utoronto.ca/hnc/publish/index.htm].

Murdie RA, Chambon AS, Hulchanki JD, Teixeira C (1995). Housing issues facing immigrants and refugees in Greater Toronto: Initia findings from the Jamaican, Polish and Somali communities. [http://www.library.utoronto.ca/hnc/publish/index.htm].

Novac S (1996). Immigrant enclaves and residential segregation: Voices of racialized refugee and immigrant women. [http://www.library.utoronto.ca/hnc/publish/index.htm].

Peach C (1998). South Asian and Caribbean ethnic minority housing choice in Britain. Urban Stud. 35:1657-1680.

Pyke J, Lowe J (1996). Supporting people, not structures: Changes in the provision of housing support. Psychol. Rehab. J., 19:5-14.

Roscigno VJ, Karafin DL, Tester G (2009). The complexities and processes of racial housing discrimination. Social Problems 56:49-69.

Soholt S (2001). Ethnic minority groups and strategies in the housing market in Oslo. Eur. J. Housing Policy 1:337-356.

Zetter R, Pearl M (1999). Sheltering on the margins: Social housing provision and the impact of restrictionism on asylum seekers and refugees in the UK. Policy Stud. 20:235-254. 